\title{
Eliciting Managerial Cognitions - The Role of Cognition in Management Research
}

\author{
Timo-Pekka Uotila
}

\begin{abstract}
The study of managerial cognitions have intrigued scholars of management for some time because of its potential to peek into the hidden thought processes behind managerial decision and sense-making. This paper introduces some of the different cognitive approaches used within the management research. The focus in this paper is two-fold. First, the literature is reviewed to present the theoretical background of cognition research within management literature. Second, a number of different cognitive mapping methodologies are introduced as ways to elicit managerial cognitions. The paper closes with managerial implications and discussion on the use of cognitive mapping methods in organizational setting.
\end{abstract}

Index Terms-Cognition, cognitive mapping, decision, sense making.

\section{INTRODUCTION}

Webster's dictionary suggests that cognition is 'the act of knowing'. This process definition suggests that cognition includes both the possession of knowledge and the conscious or unconscious mental processing of knowledge [1]. Further, Brymer et al. (2012: 121) describe the nature of cognition as follows: "Cognition involves the mental processing that uses, changes, enacts, recalls, stores, sense, and transforms knowledge in a dynamic, recursive manner. To be cognizant is to be actively aware of a set of knowledge, including a framework, within which such knowledge might be used, based on environmental or mental cues". Cognition thus plays a role in which kind of knowledge is considered as a noise and which kind of knowledge is further processed both consciously and unconsciously.

As the role of knowledge in organizations has dramatically expanded, the focus has turned on the ways how we interpret our surroundings. This has led to the studies on the way how managers in organizations interpret both external and internal organizational environment. Indeed, managerial cognition has been in the focus of management researchers for at least since 1980s, and increased its popularity in the 1990s, even though there are some earlier publications. Several books have been published from the topic [2], [3] and it has been on the subject of many special issues in leading journals [4]. The study of cognitions aims to understand the actions we make in everyday settings. Its focus on the processes inside the individual mind and their relation to one's environment aids us to make visible the previously tacit or hidden elements that guide our actions. It also provides with new categorizations and interpretative frameworks for different situations. By

Manuscript received September 1, 2013; revised November 12, 2013.

Timo-Pekka Uotila is with the University of Vaasa, Finland (e-mail: timo-pekka.uotila@uva.fi). studying these frameworks one can try to understand how individuals make sense of their environment. The visualization of the frameworks may also help to create common understanding of the different ways people perceive the world. The cognition-action relation is important as cognitions are not static, but constantly co-evolving as individual interacts with the world. Through this enaction the cognitions shape our surrounding world, while our surrounding world shapes our cognitions [5].

\section{MANAGEMENT RESEARCH AND COGNITIONS}

\section{A. The Formation of Cognitions}

There are multiple sources that influence the formation of cognitions. Different beliefs managers hold guide their decisions in organizations. Sproull [6] suggests a classification of executive beliefs used in management studies. In this classification, used widely in management studies (see for example [7], [8]), beliefs are classified into phenomenological beliefs, causal beliefs and normative beliefs. Phenomenological beliefs describe certain entities, such as nature or the perceiver itself. Causal beliefs are beliefs about certain cause and effect relationships we hold in our world. Normative beliefs are beliefs about desired state of certain phenomena. Causal and normative beliefs are often in the focus of management research; however, all of these beliefs are at least partly interrelated.

There is no single explanation about how managerial beliefs are formed [7]. However, there are two main explanatory mechanisms that have effect on the formation of managerial cognition. Laukkanen [7], studying the causal beliefs of the managers, divided these sources to individual and social processes. First, there is inherent capability of humans to inductively understand and categorize their environment. The understanding of the environment is not completely data driven, as previous theories about environment also guide our actions. Secondly, even though we have our innate theories and receive data from the environment, our actions do not happen in an isolated bubble. The concepts and causal notions are also adopted from our social environment, be it cultural, professional or organizational [7].

It is argued that the formation of individual cognitions happens through micro- and macro levels. In micro level the individual itself regulates and processes information around his/her environment. In macro level the environment (society, industry, etc.) shapes the individual thinking. These two levels are also reciprocal, thus that individual thoughts are manifested in action in a certain environment, thus that individual shapes the environment through his/her action, 
and on the other hand environment builds a background which restrains individual through institutional (e.g. law) and social (e.g. culture) means.

One of the theories that try to understand human thought in social setting is the theory of social cognition, which can be described through certain basic features: unabashed mentalism, orientation toward process, cross-fertilization between cognitive and social psychologies, and at least some concern with real world social issues [9]. Theory of social cognition states that during our everyday life we encounter situations where we have to make decisions and which require explanation. In these situations we use causal analysis to determine what happened. Causal analysis refers thus to the process where we try to identify which factors or elements lead to different outcomes. This process can be implicit or it can be more conscious (for example as in case for CEO thinking about the elements of success or performance of his/her company). The basic principles of cause-effect relations are already learned as a child and they are also later on used as adults make causal judgments in an uncertain environment [9]. There are three such basic principles: The first principle is the one that cause precedes effect, which is already learned by the age of three. The second principle is that people tend to see factors that have temporal contiguity with effect. This means we are more inclined to assume the factors that happened just before the outcome as causes in relation to factors that happened longer time ago. The third basic principle is the spatial contiguity, meaning that factors spatially near the outcome are considered as causes more easily compared to factors happening far away from the outcome. It is important to understand the role of the underlying principles as they happen to form our causal explanations of our surrounding environment. The surrounding environment is interpreted through the individual cognitions, sometimes labeled as schemas, mental models or frameworks. Moreover, Fiske and Taylor (1991: 98) follow the previous literature and define schema as a cognitive structure that represents knowledge about a concept or type of stimulus, including its attributes and the relations among those attributes. Schemas are used in our conceptually driven processing of our surroundings. Different concepts in our schemas come from multiple sources as we are constantly constructing our reality.

Our cognitions of this world are consequences of multiple forces that guide our thinking and actions. We as a human beings are able to reflect our past and think in advance about our futures. Moreover, our social contacts influence how we perceive things and what things become a part of our worlds. According to Bandura [10] there are three factors that constitute the formation of individual perceptions: behavioral, cognitive and personal, and environmental factors. These factors form the triadic reciprocity, meaning that all these factors work in ensemble. Bandura uses the term triadic reciprocal determinism to illustrate the mutual action between causal factors.

To illustrate this, people have a power to choose a certain environment by behaving a certain way. For instance, CEO has at least some power to determine his closest colleagues. By using a cognitive judgment CEO can use his own behavior to choose certain members of a board, which he/she thinks provide the most meaningful information concerning the business environment. In addition of choosing a certain environment, people also create their environment through their actions. By doing this, people strive to achieve some regularity in their lives [10].

Moreover, we receive information from our surrounding environment and interpret it in a different fashion. Walsh [11] states, that we can approach information processing by using two dominant ways. These are theory driven or top-down approach, and data driven or bottom-up approach. In the theory driven approach, individual's knowledge structure and past experiences from similar events guide processing of information, whereas in data driven approach the information acquired from the environment itself shapes the individual response to it. In everyday life, the theory driven approach is used more often, whereas data driven approach is used only in a most novel situations [11].

\section{B. Cognitions in Management Research}

The cognitive perspective of the organizations is based on the vast work of the Carnegie school researchers, and subsequent pieces, such as Administrative behavior [12], Organizations [13], and a Behavioral theory of the firm [14]. In addition, Weick's [5] the social psychology of organizing laid foundations for the cognitive perspective of the firm.

The roots of this stream of thought can be found especially from March and Simon's [13] and Cyert and March's [14] studies on bounded rationality, which argued that the basis for the decisions can be found from the managers assumptions about future events, the knowledge of the alternatives and further the consequences of the alternatives. This article draws from the managerial and organizational cognition literature [15]-[17]. The managerial cognition research shows that different schemas or frameworks managers have direct attention and have effect on the interpretation managers make. Managers face constantly complex problems, which require cognitive efforts. In order to cope with the flow of information, managers form beliefs structures - simplified representations of the world - to aid them in the everyday decision making [12], [13]. These belief structures are automatically created, as the managers need tools to face the complexity of their environment and information in it [18]. There is plenty of research focusing on the managerial cognitions and their outcomes which has created path for the present studies [19], [20], [2]. The research interests have been, for example, on following questions: how managers' attention guides action in organization [21], [22], how managers' cognition affects the strategy process [2], and how different strategic thinking effect the strategy development and implementation (see Walsh [11] for a review). Managerial cognitions have been analyzed most in the area of strategic management (e.g. [16], [2], [23]-[25]), but for example rarely in the area of human resource management. In addition, from a decision making perspective, it is suggested that strategic decision making and implementation are both improved through managers' sharing homogenous cognitions of competition e.g. [20], developed and collective cognitive cognitions among top management increases the effectiveness of decision making [16], help attainment of objectives and learning in complex 
situations [26], and support handling the uncertainty inherent in decision making [27].

\section{INDIVIDUAL AND SOCIAL COGNITIONS}

The individual approach stems from the perspective that managers have certain cognitive schemas, or mental models, which guide their action and shape their interpretative worlds. The focus of this research stream is individual itself. Information processing school was one of the first to focus on the organizational decision makers striving towards rationality limited by their cognitive capacities and available information [12], [13]. Later Weick [28], [5] presented his concept of sense making and has been one of the most influential writers in this area. The concept on sense making has molded the discussion of management greatly. Sense making stems from the interpretative paradigm of organizational and sociological analysis [29]. Sense making refers to "...such things as placement of items into frameworks, comprehending, redressing surprise, constructing meaning, interacting in pursuit of mutual understanding, and patterning" (Weick 1995: 6).

Sense-making is understood as a process, which includes seven properties: it is grounded in identity construction, it is retrospective, it is enactive of sensible environments, it is social, it is ongoing, it is focused on and by extracted cues, and it is driven by plausibility rather than accuracy [5]. However, Weick [5] highlights that these seven characteristics are not meant to be as strict set of properties to be tested, but rather as raw material for outside observer. Weick [28] argued that the part of being in the world includes sense making of the nearest environment. Through the sense making individuals try to understand their environment and literally "make sense" what is happening around them. Sense making refers thus to conscious categorizations of individual environment. These categories form representations to the minds of the individuals. It is thought that through this categorization it is possible for individual to understand his/her surroundings.

Another approach to study cognitions is to study collective cognitions of individuals. Group, organization and industry level research on cognition form the social approach of cognition. Especially the research made at the industry level has been one of the most influential [30], [31]. For instance, Spender [31] studied the managerial cognitions and came to the conclusion that there exist certain industry wide representations, called recipes, or heuristics, which act as a basis for the managerial decision making. Another influential study has been the study conducted by Porac et al. [30]. In their study, Porac et al. [30] studied the way how managers in Scottish knitwear industry perceive their competitors. As a conclusion, they found that "rivalry" was a collective cognitive construct, and was based on a group of firms that managers identified as competitors. Moreover, the way how managers categorized their competitive environment was reflected in the managers' interpretations and actions, thus affecting the formation of the competitive environment [25].

The firm's competitive environment has been in the focus on the managerial cognition research field. Researchers have studied how managers simplify the external reality by conceptualizing competitors, market boundaries and strategic groups [32]. This line of research suggests that managers own mental models which are more or less similar across the certain groups, organizations or industries [10]. This can be seen in the research of Spender [31], who argued on the behalf of industry recipes, industry wide representations of the managers on prevailing industry. However, Daniels et al. [32] reports that there has been some mixed results and a debate on a question whether managers form their mental models based on the organizational structures and processes [28], [33], or if the mental models are more a consequence of extra-organizational environment [30]. Daniels et al. [32] in their study of the effect of task and institutional influences on managers' mental models of competition came to a conclusion that neither of the approaches presented early are superior to another, but noted that especially middle level managers mental models were similar across the industry. They also reported that senior managers' mental models differed between the organizations, being thus more affected by the task environment of the organization. Thus, both task and institutional elements should be taken into account when studying cognitions

\section{Eliciting Managerial COGNITIONS}

\section{A. Cognitive Mapping as a Research Method}

One way to study cognitions is to draw cognitive maps of the mental models of researched subjects. This is called cognitive mapping. The background of the cognitive mapping techniques can be found from the cognitive science and areas related to it, such as cognitive anthropology, artificial intelligence and linguistics [2]. Cognitive mapping techniques are used to elicit the structure and the content of people's mental models [32]. In other words, cognitive mapping rests on the idea that we can visualize the representations of the individuals in order to understand the logic behind the individual thinking better. Mental models, schemas or representations are ways how individuals store information from their environment. Using the help of these representations individuals make sense of their environment [5]. However, it is never possible to capture the "real" living world of the respondent. When cognitive map is ready, it has gone through the transformation process from subject's mind into subject's representation, subject's discursive representation, and researcher's representation [35].

\section{B. The Use of Cognitive Mapping Methods}

Cognitive mapping technique is often used as a methodological tool in research on managerial cognitions. It is used to assess the structure and content of individuals' mental models of given issues and obtain graphical representations of individual understanding of a particular issue at a particular point in time and place [32], [36]. Therefore the drawn cognitive maps are highly context-bound [32]. Further, it is different compared to traditional content analysis thus that in addition to giving information "what" individuals are thinking it gives information "how" individuals arrange their thoughts and what are the relationships between different contents in their 
thought processes [37], [32]. Laukkanen [38] lists five ways to use cognitive maps: (1) to analyze discourse itself (2) model a domain of reality where respondents live, (3) study respondents interlinked, domain-related knowledge and/or belief-base (such as ideology or worldview) (4) to map cognitive structures (schemas, cognitive maps, mental models), and (5) to study cognitive processes, the way how respondents generate their answers (algorithms, heuristics).

There are two ways to conduct cognitive maps; ideographic and nomothetic. Other researchers rely on the ideographic research methods e.g. [39], [34], whereas other relies on the nomothetic research methods e.g. [40]. Researchers relying on the ideographic research methods use open ended questions to elicit cognitive maps of the managers. Moreover, they often see that managerial mental models are diverse instead of homogenous, and that this diversity increases as company and functional boundaries are crossed [16]. Researchers using nomothetic methods on the other hand use more structured methods to gather information of cognitive maps of the managers and more often assume similarity of cognitive maps.

Ahmad and Ali [36] state that cognitive mapping is not a technique itself; it is an umbrella term for many techniques that visualize the individual's understanding of particular problem or issue. They continue that the good sides of cognitive mapping can be divided into two categories: the technique itself and the use of results obtained. As a technique, the maps provide for example structured thought through symbolic representation, graphical rather than linear layout, and a tool to handle large amount of qualitative data. Results as graphical illustration of interviewee's thinking can be used for example to form a common understanding on a researched topic. Moreover, Laukkanen [38] states that cognitive mapping (or cause mapping) is not critically sensitive to underlying theoretical assumptions and can thus be used in wide variety of research domains.

TABLE I: COGNITIVE MAPPING PROCESS (CHANEY 2010)

\begin{tabular}{l|l}
\hline Step & Description \\
\hline 1. planning, preparation & $\begin{array}{l}\text { Getting familiar to literature } \\
\text { and themes } \\
\text { Getting familiar with concepts } \\
\text { and language } \\
\text { Structured or non-structured } \\
\text { methods } \\
\text { Rough transcription, }\end{array}$ \\
3. data collection & $\begin{array}{l}\text { preliminary analysis of data } \\
\text { Breaking text into assertions, } \\
\text { Structure and content } \\
\text { visualization }\end{array}$ \\
\hline
\end{tabular}

Cognitive mapping process follows the principles of qualitative research [35] (Table I). The process starts with the planning and pilot interview processes, continues through the data collection phase (ideographic or nomothetic methods), transforming the interviews into same language and finally into analysis and visualization of the data. Naturally, the process is not necessarily linear.

\section{Technological Aids for Cognitive Mapping}

Cognitive maps can be drawn manually, but especially in cases where the number of recipients is high, the computer aided techniques become necessities. There are various computer programs designed for eliciting cognitive maps, such as Decision Explorer, Cognizer and CMAP3. The programs differ from each other for instance in the number of recipients used in drawing the cognitive maps. Decision explorer program can be used to elicit individual managers' cognitive maps; whereas CMAP3 is more suitable for drawing a map based on the multiple recipients answers. Moreover, programs also differ in the nature of the questions; Cognizer program uses structured research question methods, whereas CMAP3 can be used both on the structured and non-structured research settings [41].

\section{CONCLUSION}

Manager's interpretations of their organizational environment - both external and internal - affect their actions and decisions. This finding or realization has turned the attention towards the frameworks managers use for decision making in organizations. The roots of the cognitive perspective of the organizations can be found on the vast work of the Carnegie school researchers. This perspective took information processing and decisions as the unit of analysis of organizations. The research stream was influential in its time and still continues to influence management scholars (cf. [43]). Another, more interpretative point of view is provided by Weick [5], whose concept of sense-making has also been greatly influential.

Even though the roots of the cognitive perspective can be found from the late 1940s and on the Carnegie school researchers, the advent of the cognitive perspective was on the beginning of 1990s. Since that, the managerial and organizational cognition research has exploded, and spread into multiple research domains. Managers' interpretations of their business environments effect the way how organizational activities are arranged. Further, managers' actions based on those interpretations shape the business environment. Through the cognitive mapping methods these assumptions can be made visible. By visualizing the managerial cognitions it is possible to create common understanding in a company, for example among the management board, or it can be used as a tool for recognizing false assumptions.

\section{REFERENCES}

[1] R. A. Brymer, M. A. Hitt, and M. Schijven, "Cognition and human capital: the dynamic interrelationship between knowledge and behavior," in A.Burton-Jones \& J.-C. Spender (ed.) The Oxford Handbook of Human Capital, Oxford: Oxford University Press, 2011.

[2] A. S. Huff, Mapping Strategic Thought, Wiley: Chichester, 1990.

[3] R. Axelrod, Structure of Decision: The Cognitive Map of Political Elites, Princeton University Press, 1976.

[4] G. P. Hodgkinson, "Editorial introduction to the special issue: Thinking in organizations," Journal of Management Studies, vol. 34, no. 6, pp. 845-850, 1997

[5] K. Weick, Sensemaking in Organizations: Sage, 1995.

[6] L. S. Sproull, "Beliefs in organizations," in P. C. Nystrom and W. H. Starbuck (eds.), Handbook of Organizational Design: Remodeling Organizations and their Environments, vol. 2, Oxford University Press, London, 203-224, 1981.

[7] M. Laukkanen, 'Understanding the formation of managers' cognitive maps: a comparative case study of context traces in two business firm clusters," Acta Academicae Oeconomicae Helsingiensis, Helsinki, 1989. 
[8] P. Chattopadhyay, W. Glick, C. Miller, and G. Huber, "Determinants of executive beliefs: Comparing functional conditioning and social influence," Strategic Management Journal, vol. 20, pp. 763-789.

[9] S. Fiske and S. Taylor, Social Cognition, McGraw-Hill, 1991.

[10] A. Bandura, "Social foundations of thought and actions: A social cognitive theory," Englewood Cliffs, NJ: Prentice-Hall, 1986.

[11] J. Walsh, "Managerial and organizational cognition: Notes from trip down memory lane," Organization Science, vol. 6, no. 3, pp. 280-321, 1995.

[12] H. A. Simon, Administrative Behaviour, 1st ed., the Free Press, 1945.

[13] J. G. March and H. A. Simon, Organizations, New York: Wiley, 1958.

[14] R. M. Cyert and J. G. March, A Behaviral Theory of the Firm. Englewood Cliffs, NJ: Prentice-Hall, 1963.

[15] I. Clarke and W. Mackaness, "Management 'Intituition': An interpretative account of structure and content of decision schemas using cognitive maps," Journal of Management Studies, vol. 38, no. 2, pp. 147-172, 2001.

[16] K. Daniels, G. Johnson, and L. de Chernatony, "Differences in managerial cognitions of competition," British Journal of Management, vol. 5, pp. 21-29, 1994.

[17] S. Nadkarni and P. Barr, "Environmental context, managerial cognition, and strategic action: an integrated view," Strategic management journal, vol. 29, pp. 1395-1427, 2008.

[18] R. L. Daft and K. E. Weick "Toward a model of organizations as interpretive systems," Academy of Management Review, vol. 9, no. 2, pp. 284-295, 1984.

[19] C. Eden and F. Ackermann, "The analysis of cause maps," Journal of Management Studies, vol. 29, no. 3, pp. 309-324, 1992.

[20] J. F. Porac and H. Thomas, "Taxonomic Mental Models in Competitor Definition," Academy of Management Review, vol. 15, pp. 224-240, 1990.

[21] R. D. Aveni and I. C. MacMillan, "Crisis and the content of managerial communications: A study of the focus of attention of top managers in surviving and failing firms," Administrative Science Quarterly, vol. 35, pp. 634-657, 1990 .

[22] W. Ocasio, "Towards an attention-based view of the firm," Strategic Management Journal, vol. 18, pp. 187-206, 1997.

[23] R. Reger, "Management thought structures and competitive positioning," In A. Huff (ed.), Management Thought Structures and Competitive Positioning, Wiley: New York, 1990.

[24] R. Reger and A. S. Huff, "Strategic groups: A cognitive perspective," Strategic Management Journal, vol. 14, pp. 103-124, 1993.

[25] S. Kaplan, "Research in cognition and strategy: Reflections on two decades of progress and a look to the future," Journal of management studies, vol. 48, no. 3, pp. 665-695, 2011.

[26] J. W. Dean and M. P. Sharfman, "Does decision-process matter? A study of strategic decision-making effectiveness," Academy of Management Journal, vol. 39, no. 2, pp. 368-396, 1996.

[27] M. A. Korsgaard, D. M. Schweiger, and H. J. Sapienze, "Building commitment, attachment, and trust in strategic decision-making teams: The role of procedural justice," Academy of Management Journal, vol. 38 , no. 1 , pp. 60-84, 1995.
[28] K. Wecik, The Social Psychology of Organizing, $2^{\text {nd }}$ edition, 1979.

[29] G. Burrel and G. Morgan, Sociological Paradigms and Organizational Analysis: Elements of the Sociology of Corporate Life, Ashgate Publishing, 1979.

[30] J. F. Porac, H. Thomas, and C. B. Fuller, "Competitive groups as cognitive communities: The case of Scottish knitwear manufacturers," Journal of Management Studies, vol. 26, pp. 397-415, 1989.

[31] J.-C. Spender, "Industry recipes," An Enquiry into the Nature and Sources of Managerial Judgment, Basil Blackwell LTd, UK, 1989.

[32] K. Daniels, G. Johnson, and L. Chernatony, "Task and institutional influences on managers' mental models of competition," Organization Studies, vol. 23, no. 1, pp. 31-62, 2002.

[33] G. P. Hodgkinson and G. Johnson, "Exploring the mental models of competitive strategists: The case for a processual approach," Journal of Management Studies, vol. 31, pp. 525-551, 1994.

[34] K. Daniels, L. de Chernatony, and G. Johnson, "Validating a method for mapping managers' mental models of competitive industry structures," Human Relations, vol. 48, pp. 975-991, 1995.

[35] D. Chaney, "Analyzing mental representations: The contribution of cognitive maps," Recherche et Applications en Marketing, vol. 25, pp. 93-116, 2010.

[36] R. Ahmad and N. A. Ali, "The use of cognitive mapping technique in management research: Theory and practice," Management Research Review, vol. 26, no. 7, pp. 1-16, 2003.

[37] K. E. Fletcher and A. Huff, "Argument mapping," in A. Huff (ed.), Mapping Strategic Thought, Chichester: Wiley, 1990.

[38] M. Laukkanen, "Comparative cause mapping of organizational cognitions," Organizational Science, vol. 5, no. 3, pp. 322-343, 1994.

[39] K. Daniels and G. Johnson, "On trees and triviality traps: Locating the debate on the contribution of cognitive mapping to organizational research," Organization Studies, vol. 23, no. 1, pp. 78-81, 2002.

[40] G. P. Hodgkinson, "The cognitive analysis of competitive structures: A review and critique," Human Relations, vol. 50, pp. 625-654, 1997.

[41] M. Laukkanen and P. Eriksson, "New designs and software for cognitive causal mapping," Qualitative Research in Organizations and Management: An International Journal, vol. 8, no. 2, pp. 122-147, 2013.

[42] G. Gavetti and J. Rivkin, "On the origin of strategy: Action and cognition over time," Organization science, vol. 18, no. 3, pp. 420-439, 2007.

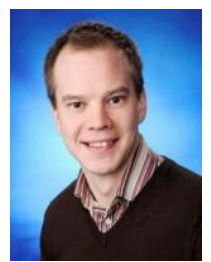

Timo-Pekka Uotila received his M.Sc. (Econ. \& Bus. Adm) degree from the University of Vaasa, Faculty of Business studies, Finland, in 2010. He is currently a researcher and $\mathrm{PhD}$ candidate at the University of Vaasa. His main research interests include human resource management, management development and managerial cognitions. 